\title{
PROTECTED AREAS AND NATURAL LANDSCAPES - AN ESSENTIAL FACTOR FOR SUSTANABLE DEVELOPMENT OF ECOTURISM IN MOUNTAINOUS REGIONS
}

\author{
Elene Salukvadze ${ }^{1}$
}

\begin{abstract}
Development of ecotourism requires providing conditions for creating reserves, national parks and other protected areas, which are the main objects of ecotourism of nowadays in Georgia. At present the country counts 90 different statuses of protected areas. Preserving them in their natural form and using their potential for ecotourism is of high significance nowadays. There is a tight relation between tourism and environment. Unaffected nature provides adequate quality of life for local tourists, whereas for foreign travelers it is an incentive to visit Georgia to see the natural monuments of the country. The paper shows the significance of protected areas in the development of ecotourism in Georgia on the example of two mountainous regions - Guria and Racha. The work considers a scientifically corroborated hypothesis that there is a great potential of transforming the first newly formed protected area in Guria - Pontine Oak Reserve and the high quality landscapes (mixed and dark-coniferous forests and sub-alpine meadows) on the territory of adjacent ( $4 \mathrm{~km}$ distance) resort Bakhmaro and its vicinities into national park in the future. The work shows that against the background of planned protected areas, there is a resource potential in Racha, which will enable to create a category of protected areas in the near future in the region. It, in its turn, will provide improvement of social-economic conditions of the region. For the fulfillment of the work we used the material of field expeditions and observations carried out in 2009-2016 in resort Bakhmaro and its vicinities and in 2019 in Racha.
\end{abstract}

Keywords: Ecotourism, Protected areas, Natural - resources potential.

\section{Study Area}

Ecotourism is tightly associated with protection of rare and endemic species of flora and fauna, the most of which are exotic and at the same time are the objects of ecotourism. Eventually, it includes the whole natural-territorial complexes landscapes as well. Quite often, tourists and holidaymakers make advantage of not passive but active travelling and rest in nature.

Ecotourism, especially in association with protected natural territories, contributes to nature protection. The majority of protected areas, especially national parks, are formed in order to protect the ecosystem and develop tourism in the region.

Worldwide Fund actively supports development of ecotourism for Nature (WWF), which makes researches for encouraging ecotourism in developing countries. The fund has greatly contributed to the formation of Borjomi-Kharagauli national Park in Georgia.

\footnotetext{
${ }^{1}$ Vakhushti Bagrationi Institute of Geography of the Tbilisi Ivane Javakhishvili State University. Tbilisi, Georgia
} 
Development of ecotourism in the mountainous regions of Georgia is primarily determined by its nature, which is diverse, unique and attractive, and at the same time, it can be used for cognitive and adventurous goals. Moreover, in its every component we can meet resources for healing, recreating, rest, sport and aesthetics. International nature protecting organizations (European Landscape Convention, WWF etc.) are actively involved in formation of the network of protected areas in order to preserve the high-mountainous ecosystems.

In June, 2019 the first protected area - Pontine Oak Reserve was formed in Guria. Founding a protected area provides protection, restoration and preservation of the biological diversity of the natural ecosystems, flora and fauna, especially the species of wild animals and plants on the verge of extinction, which are listed in the "Red Book" and "Red List" of Georgia.

Pontine Oak Reserve is located in the Chokhatauri Municipality of Guria Region and covers a 443-ha territory (mineral (acidic) water area) of the forest territory of Chokhatauri. It is located near the Bakhmaro-Chkhakoura arterial highway, on a small segment of the Lashi Mountain, in the ravines of the rivers Telvanis Ghele and Dzegvelas Ghele. Pontine Oak is an ancient species, which has been entered in the "Red Book" of Georgia and is on the verge of extinction. In Georgia, it is presented as small groups or specimens. The height of its distribution varies from $800 \mathrm{~m}$ to 1250 $1850 \mathrm{~m}$ above sea level. Pontine Oak is a high bush or a small tree. In Georgia its distribution area starts from Abkhazia, continues to Adjara and Guria and reaches the slopes of Karchkhali, Murghuli and Ponto mountains in Turkey. Generally, in Georgia it is presented as small groups or specimens in Kintrishi Protected Area, in the vicinities of the national parks of Machakhela and Mtirala. Large copses of Pontine Oak are met only on the Bakhmaro Ridge. Pontine Oak grows on well-illuminated, south-eastern and south-western slopes, in dark grey soil. Pontine Oak copses are met in the belt of beech forests, also sparse and warped sub-alpine forests.

The species of Pontine Oak is an extremely interesting plant. In fossilized flora there is not yet found any Pontine Oak or any species somehow similar to it. Generally, in the diverse family of oaks (approximately 600 species) there is no species more or less similar to it. Therefore, its uniqueness is quite obvious.

In Pontine Oak Reserve the vegetation cover is presented as four kinds of formations: 1) the Pontine Oak copse, in formation of which other species do not take part (pure copse); 2) a formation in a Colchian mixed forest; 3 ) a formation in a beech forest with a Colchian undergrowth; 4) a formation mixed with a birch forest (Surmava, Moistsrapishvili, 2018).

The landscapes with mixed and dark coniferous forests and sub-alpine meadows in the vicinities of Pontine Oak Reserve, which are located in the territories of resort Bakhmaro and its adjacent area, make a precondition and have a great potential for creating a category of either a national park or a protected area in the future. Establishing a national park will contribute to the protection of the unique nature of resort Bakhmaro and its vicinities and social-economic development in the region. In the national park there can be arranged seven different kinds of areas: a zone of traditional use, a zone of effective protection, a restoration zone, a visitors' zone and a historical-cultural zone managed by the administration together with the population. In the zone of traditional use, it will be admitted to use the natural renewable resources 
and thus, mowing, grazing, wood chopping, gathering non-timber forest formations like mushroom, berries, etc. will be available for the local residents,

The need of transforming Pontine Oak Reserve into a national park in the future can be supported by the fact that the territory of Pontine Oak Reserve is covered with well-preserved forests characteristic of the landscapes of the north-western part of the Lesser Caucasus, it is located on the area adjacent to resort Bakhmaro and here Pontine Oak copses have been preserved in the best state. As far as the territory is located separately and is difficultly reachable and well-protected, we can consider it as a "shelter" for species of animals and plants. Among them are many endemic and relict species. The forests here are characterized with relict undergrowth, among which are evergreen shrubbery: Cherry laurel (Laurocerasus officinalis), Rododendron pontic (Rhododendron ponticum), Holly (Ilex colkhica), Butcher's-broom (Ruscus ponticus) etc. This will enable to preserve the bio-diversity of the northwestern part of the Lesser Caucasus. On the territories of Pontine Oak Reserve and adjacent resort Bakhmaro and its vicinities, by distribution type, we can distinguish the following ones out of the existing 41 timber plant species (Results of Chokhatauri Forest.., 2017): well distributed (5), distributed (19), rare (9) and very rare (8) species (Fig.1.).

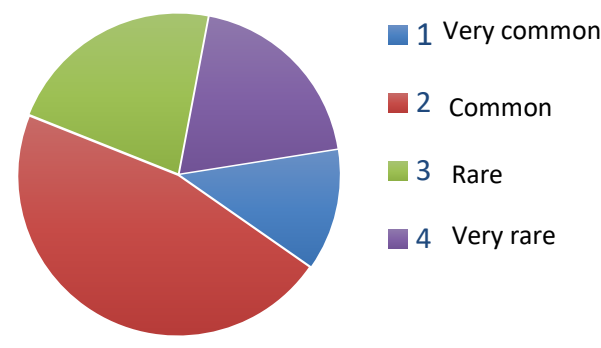

Fig. 1 Characteristics of forest wood species in terms of distribution

well distributed and distributed timber species include those shown in (Table 1):

Table 1. List of tree species and their status

\begin{tabular}{|c|c|c|c|c|}
\hline \multicolumn{3}{|c|}{ Wooden species } & \multirow{2}{*}{$\begin{array}{l}\text { Very } \\
\text { Distributed }\end{array}$} & \multirow{2}{*}{ Distributed } \\
\hline № & English name & Latin name & & \\
\hline 1 & Caucasian alder & Morus alba & + & \\
\hline 2 & Caucasian hornbea & Carpinus caucasicus & + & \\
\hline 3 & Oriental beech & Fagus orientalis & + & \\
\hline 4 & Oriental hornbeam & Carpinus orientalis & + & \\
\hline 5 & Cherry laurel & Laurocerasus officinali & + & \\
\hline 6 & Caucasian fir & Abies nordmaniana & & + \\
\hline 7 & Caucasian spruce & Picea orientalis & & + \\
\hline 8 & Caucasian pine & Pinus sosnowskyi & & + \\
\hline
\end{tabular}




\begin{tabular}{|l|l|l|c|c|}
\hline 9 & Georgian oak & Quercus iberica & & + \\
\hline 10 & Caucasian Willow & Salix caucasica & & + \\
\hline 11 & Sweet chestnut & Castanea sativa & & + \\
\hline
\end{tabular}

Rare and very rare distributed timber species include those shown in (Table 2).

Table 2. List of tree species and their status

\begin{tabular}{|l|l|l|c|c|}
\hline \multicolumn{2}{|c|}{ Wooden species } & Rare & Very rare \\
\hline № & English name & Latin name & & \\
\hline 1 & White mulberry & Morus alba & + & \\
\hline 2 & Field maple & Acer campestre & + & \\
\hline 3 & Norway maple & Acer platanoides & + & \\
\hline 4 & Caucasian lime & Tilia caucasica & + & \\
\hline 5 & Litwinow's birch & Betula Litvinovi & + & \\
\hline 6 & Pontic oak & Quercus pontica & + & \\
\hline 7 & Lebanon cedar & Cedrus Libani & & + \\
\hline 8 & Wych elm & Ulmus glabra & & + \\
\hline 9 & Walnut & Juglans regia & & + \\
\hline 10 & Wild service tree & Sorbus torminalis & & + \\
\hline 11 & Yew & Taxus baccata & & + \\
\hline 12 & Black mulberry & Morus nigra & & + \\
\hline 13 & European ash & Fraxinus excelsior & & + \\
\hline
\end{tabular}

Pontine Oak Reserve offers good possibilities for ecological education and ecotourism development. Resort Bakhmaro adjacent to Pontine Oak Reserve (4 km distant from the reserve) and resort Nabeghlavi (20 km distant from the reserve) make good conditions for development of recreational zones. Considering it will be a quite timely and necessary activity (in case of creating a national park) for improving the state of the unique coniferous forests on the territory of resort Bakhmaro and its vicinities. The resort territory is mostly covered by dark coniferous forests, namely, spruce and fir trees. These landscapes are the mostly loaded (in the way of recreation digression, forest clearance, and livestock grazing). The landscapes are characterized with sparse forests. Although there is quite considerable quantity of young growth, in early summer, when the population drives the wintering cattle to the area, then it becomes extremely ill-used. Among the territories adjacent to the resort, the most area $\left(9.2 \mathrm{~km}^{2}\right.$, i.e. $25 \%$ of the whole territory) is covered with sub-alpine secondary meadow-shrubbery and sub-alpine meadows. Quite a large territory is covered with secondary meadows, which are at some places covered with weed (false hellebore, mat-grass, wild sorrel). The general image in regards to landscape is as follows: dark coniferous forests (spruce and fir forests, fir forests, spruce forests) are dominating. In the eastern part of the resort, we meet pure beech forests $\left(1.65 \mathrm{~km}^{2}\right.$, i.e. $4 \%$ of the whole territory), also beech and dark coniferous forests (area $2.59 \mathrm{~km}^{2}$, i.e. $7 \%$ of the whole territory). Only a small territory is occupied with pine forests $\left(0.34 \mathrm{~km}^{2}\right.$, i.e. $1 \%$ of the whole territory) (Salukvadze, Khechikashvili, et al. 2010).

The general load made by holidaymakers (c. 10000 people) together with cattle owners, who live here temporarily and seasonally often leads the dynamics of the natural complexes (landscapes) to deplorable conditions. Sparsity in the forest is great. 
Trees damaged by bark beetles are frequently met here. The quantity of growing plants is quite fair, though still insufficient as a result of unmanageable forest chopping and cattle grazing, which is now often observed even on the territory of the resort (in summer a certain part of the Adjarian migratory population drives its cattle to this territory to use pastures. They live the whole summer season here, make dairy products and sell them at the very place). Consequently, many cut trees are met at many places alongside the river Bakhvistskali. The forest is sparse. An anthropogenic load after certain time causes changes in the state of landscapes. In its turn a landscape is characterized with self-restorability, which provides its resistance to influencing forces. However, when the load is intense, i.e., it takes place for a long period, then the resistance of the landscape reduces and it starts to degrade. The degree of damage caused by exogenic and endogenic forces increases, the intensity of disintegration and washing away of upper layers of soil becomes stronger, which leads to ecocide in the landscape. The following processes take more times and cause destruction in the main geologic foundation (basic rocks), which, in its turn, results in geo-cide in landscapes, i.e., a complete destruction (Beroutchashvili, Nesterenko, 1973).

Arrangement of a national park, on the one hand, considers the local socialeconomic and traditional-cultural requirements, and on the other hand, its main function is to protect and preserve wild nature. A national park zone must cover especially vulnerable ecosystems and those, which have not yet undergone anthropogenic changes.

In case Pontine Oak Reserve becomes a national park in the future it must be effectively protected, i.e., become a zone of strict control.

A zone of traditional use. Usage of certain resources must be admitted, for example, using those resources that do not have much influence on the environment and are easily manageable. The population living in the vicinities of the national park should be allowed to make traditional use of the territory. Such usage must be easily manageable and this will be a quite timely activity as far as the population (migratory stockbreeders) has been using the alpine meadows of the territory adjacent to resort Bakhmaro for pasturing. Considerable increase in the intensity of grazing caused great ecological problems in the Alpine zones and forest landscapes: activation of erosive processes, risk of pollution in the best mountain drinking water springs, undesirable changes in the local flora and fauna, etc. For elimination of the above-mentioned major restrictions should be imposed on livestock quantity, grazing intensity and seasonal cattle migration. It is necessary to build special roads (corridors) for cattle migration. Pasturing should be strictly controlled.

Restoration zone. Distinguishing restoration zones is required to restore the landscapes of the territories, which have undergone considerable degradation as a result of anthropogenic influences.

It would be reasonable that restoration processes took place without human involvement as to prevent violation of the consequence in natural processes and selfrestoring mechanisms of the landscapes. Fortunately, on the territories adjacent to resort Bakhmaro, despite the deplorable state of the forests, the positive fact is observed that young plants are growing intensely in the places, which are not easily reachable for cattle.

Auxiliary zone. In the auxiliary zones the population will be allowed to use the lands within the park (cultivable land, forest and etc.), which will be subject to the 
protection requirements of the national park. This will provide protection and preservation of the natural landscapes and at the same time will bring economic benefits to the population.

Zoning of a national park, besides strict control areas and traditional zones, also considers distinguishing so called wild nature, where it is advisable that the environment was not significantly changed by human activities and it would be the most characteristic landscape of the park. This zone must include places with high recreation value and unique natural characteristics, also historical and cultural monuments: in Bukistsikhe - the remains of a castle dated back to early feudal age, in Goraberezhouli - a castle wall (the end of XVII century) and a church (XIX century), in Ganakhleba - a monastery complex "Udabno" (middle centuries), a church (developed middle centuries) in Zemo Erketi and etc., also the memorial museums of Nodar Dumbadze, Ana Kalandadze, Nikolai Marr, Mose Gogiberidze and the Local Museum of the region.

The national park may become a tourist center in Guria region, while it requires organizing various tours with ecological and educational purposes. Scientific investigations also could be carried out by students and scientists.

It is significant to reveal and use the energy resources (small hydroelectric powers on the rivers of Bakhvistskali, Gubazeuli and Supsa) on the territory of the national park.

The other region for our studies, Racha, is located in the northeastern part of West Georgia. It, on the Central Caucasus, on the south slopes of the main ridge of the Caucasus includes two administrative centers: municipalities of Ambrolauri and Oni. The complex, segmented relief and severe climate conditions, high-hypsometric location, extreme land shortage, great inclination of slopes do not make any favourable conditions for development of land farming here. Extracting of barite and arsenic has been stopped whereas these ores made a great contribution to the mining industry of not only the region but the whole country as well. The state of the demography in Racha is poor (the number of population in Oni Municipality is 613 and Ambrolauri Municipality it is 9129). Consequently, Racha is a less populated mountain region of Georgia. The significant part of population has abandoned their residences in really existing villages, which have only maintained the official status of village nowadays.

Nowadays in the region of Racha ecotourism has become an economic activity with a sustainable growth. The number of guest houses, hostels and small cottages for local and foreign tourists is increasing.

The territory on the Central Caucasus is among the planned protected areas. The area also includes Racha region (Oni Municipality) with its intact nature, diversity in vegetation, animals and birds, beautiful landscapes and exotic natural monuments, ancient historical and cultural heritage. Before 90 -ies of the past century, tourism was a substantial part of the industry in Racha. However, the unmanaged tourism activities led to disastrous results here - the vulnerable high-mountain ecosystems were damaged and collapsed, the environment became highly polluted. Creation of protected areas will provide preserving unique ecosystems.

The planned protected area on the territory of the Central Caucasus includes the northern part of Racha on the main ridge of the Caucasus - on the southern slopes of the peak Chanchakhi (4461 m), mountain Pasismta (3779 m), mountain Tsitelimta (3691 m), the ridges Gezevtseki (3452 m), Gurdzievtseki (3325 m) and Mamisoni 
$(2829 \mathrm{~m})$, the territories of the rivers Lukhuni, Zopkhitura, Chveshura and Chanchakhistskali, the divide ranges of Shoda-Kedela, and etc. The main goal of creating a protected area in Oni Municipality is protecting the ecosystems of the source of the river Rioni and its tributaries, which flow from the main ridge of the Caucasus, also the high-mountain ecosystems around the glaciers feeding these sources, water ecosystems and the forest ecosystems stabilizing them.

The prioritized goals of creating the protected areas are: protection of the unique and rare ecosystems; preservation of the ecosystems of the mountain Pasi and the ridge Shoda-Kedela in their natural state; preservation, protection and reproduction of the relict and endemic plants and animals distributed in the region that have entered in the Red Book; protection of the hardly survived sub-alpine forests and their constituent arboreal plants: Litvinov birch tree, Caucasian rowan, high-mountain maple tree and etc.; protection of the less changed ecosystems around the river Rioni and its tributaries; protection of the ecosystems of the forests around the resorts of Shovi, Utsera, Sortuani and Skhepuri with enormous recreation potential in order to stabilize the climate in the area; protection of cultural heritage, restoration and conservation of historical-cultural monuments, support for improvement of the social-economical state in the villages (Glola, Ghebi, Tchiora, Lagvanta, Sakao, Khideshlebi and etc.) adjacent to the protected area.

There are various types of landscapes, separate ecosystems and cenosis in the protected area. Among the vegetation cover, together with the representatives of xerophilous plants (oak, pine trees, etc. in the forests), we can meet shrubbery and herbaceous plants here, also relict plants of Colchian type. We can also meet wideleaved forests with oak, chestnut and hornbeam, beech trees, mixed dark-coniferous forest of spruce, fir, pine and beech (1100-1800 m), sub-alpine warped and sparse forests $(1800-2500 \mathrm{~m})$. In the forest there is a great quantity of wild fruits and berries and resources for hunting. Out of the presented plants here, 33 species of relict and endemic plants have entered the Red Book of Georgia (Table 3). Among them are Georgian hazelnut, chestnut, walnut tree, sea buckthorn etc. Among the representatives of fauna, the lynx, otter, black vulture, griffon vulture and others are met.

Table 3. Plants included in the Red Book of Georgia, common in the Racha region

\begin{tabular}{|l|c|c|l|}
\hline Name of the plant & Relics & Endemics & Brief description \\
\hline Yew & + & - & Tree \\
\hline Colchis boxwood & + & - & Tree \\
\hline Georgian nut & + & + & Tree \\
\hline Chestnut & + & - & Tree \\
\hline Hartvis oak & + & - & Tree \\
\hline Imeretian oak & + & + & Tree \\
\hline Walnut tree & + & - & Tree \\
\hline Colchis bladernut & + & - & Tree \\
\hline Common bladernut & + & - & Tree \\
\hline Sea-buckthorn & + & - & Buch \\
\hline
\end{tabular}


Georgian Geographical journal

\begin{tabular}{|l|c|c|l|}
\hline Common persimmon & + & - & Tree \\
\hline Yellow water lily & + & - & Perennial herbaceous plant \\
\hline Cyclamen colchicum & - & + Georg. & Perennial herbaceous plant \\
\hline
\end{tabular}

Scarcity of landscapes in the planned protected area of Racha is caused because the eastern boundary of the protected area coincides with the boundary of West Georgia. Thus, here we meet meadows of sub-alpine cereals characteristic of East Georgia and forests covered with xerophilous oak, hornbeam and tall scrubs characteristic of the mountain regions of East Georgia but rare for West Georgia, the geo-botanical zone of the Central Caucasus is also presented. Virgin forests have survived on the territory of Oni Municipality. The area of the forests covers 8960 ha, 12\% of the whole forest territory (Kandelaki, 2012).

It is possible to build small hydropower stations on the quick mountain rivers that would improve the energy supply for the population. It is also possible to manage trout farms on the rivers. Collecting healing plants and making medicine from them, collecting wild fruits, berries and mushrooms and producing food from them, collecting fir seeds, reproducing and breeding seedlings, and use of resources for hunting will provide improvement in the social-economical state of the region.

In the vicinities of the planned protected area of Racha we can meet numerous churches and towers belonging to middle and late centuries, for example the church in Utsera, the castle in Chidrota, the church of Archangel of Ghebi (developed middle centuries), tower Dedagvtisa (Mother of God), the medieval church in Gloli, Tamar's Castle and etc.

\section{Conclusion}

In Guria and Racha, the mountainous regions of Georgia, which have severe natural conditions, difficult social-economic conditions and vulnerable demographic situation (decreased reproduction, abandoned and emptied villages) and deteriorated ecologic state, development of tourism, namely, ecotourism will contribute to rationalization of land management. Using more territories for tourism purposes will bring more benefits to the region than using the lands for farming and industry would do. Development of ecotourism requires creating protected areas that will provide protection, restoration and reasonable use of natural or transformed territories distinguished for their biodiversity, also creating favourable conditions for sustainable development of recreation, health care and ecotourism in the natural and historical-cultural environment.

After creating a national park in Guria and Racha the local population will return to the abandoned homes and the income received from ecotourism will improve their economic conditions.

Development of ecotourism in the high-mountainous regions of Guria and Racha will provide preserving the natural beauty of the unique territories, decrease the full load on the environment, raise awareness of the population and provide education in nature exploitation for nature managers, broaden knowledge in pupils and make their relation harmonious with the nature.

It is important to transform certain natural areas into protected areas and protect the mountain ecology. 
Inventorying and creation of databases of natural and historical-cultural resources of the regions is of great importance. The database should be periodically updated with the information on the state of the environment; the cases of violations in ecological nature management should also be noted.

\section{References}

Beroutchashvili Nikoloz, Nesterenko Vladimir (1973) Genocid, ecocid i narušenie strukturi prirodno - territorialnix kompleksov/In: Journal: Nabludenia i issledovania na MGFS. [Genocide, Ecocide and violation of the structure of Natural-territorial complexes], in: Journal: observation and research on IFHC /Georgia, Tbilisi, \# IV, p. 12-15 (in Russian)

Kandelaki Teimuraz (2012) Rach'is regionis tq'is resursebi//nn: Rach'a: ts'arsuli, ats'mq'o, momavali/Sakartvelos mets'nierebata ak'ademiis mtis problemebis k'ompleksuri shests'avlis k'omisia. [Forest resources of the Racha region], in: Racha Past, Present, Future. Georgia, Tbilisi, p. 271-276 (in Georgian)

Ch'okhatauris tq'is inventarizaciis shedegebi. [Results of Chokhatauri Forest Inventory] (2017), Georgia, p. 33-38 (in Georgian)

Salukvadze Elene, Khechikashvili Maia, Chaladze Tamila, Lominadze George (2010) K'urort Bakhmarosa da mis shemogarenshi antropogenuri zemokmedebit gamots'veuli landshapturekologiuri mdgomareobis taviseburebani/In: Zhurnalshi:Mets'niereba da teknologiebi/ Sakartvelos Mets'nierebata erovnuli ak'ademiis q'oveltviuri samets'niero jurnali. [The Peculiarities of the Bakhmaro Landscape and Ecology Triggered by Anthropogenic Effects] Journal: Science and Technologies Monthly Scientific-Revieweed Magazine of Georgian National Academy of Ssciences/ Georgia, Tbilisi, \# 10-12, p. 50-55 (in Georgian)

Surmava Lela, Moists'rapishvili Lasha (2018) Bunebisa da adamianis harmoniuli tanaarseboba

[Harmonious coexistence of nature and man], Journal: Guria/ Georgia, Tbilisi, \# 25, p. 26-28 (in Georgian)

Ukleba David, Budag Budagov, Museib Museibov, Elena Sokhadze, Aleksandr Bagdasarov (1983), Landšaftnaja karta Zakavkazija, Glavnyi departament geodezii i kartografii - [Landscape map of the South Caucasus, (1:600 000)], Main Department of Geodesy and Cartography/Russia, Moscow. (in Russian) 